\title{
Mapping forest clearcuts using radar digital imagery: A review of the Canadian experience
}

\author{
by Brigitte Leblon ${ }^{1}$
}

\begin{abstract}
Annual clearcut mapping is currently done in Canada mainly from photo-interpretation of aerial photographs. An advantageous alternative would use digital imagery. Optical imagery acquisition depends on weather and illumination conditions, but not radar images. This paper documents the state of practice in Canada in the use of radar digital images for clearcut mapping, with regards to the type of images used, to the influence of environmental conditions, the band, polarization, time of the year, and incidence angles, as well as to the mapping accuracy. Synergism between optical and radar images is also discussed. Finally, a few experimental automated mapping systems using radar imageries are presented.
\end{abstract}

Key words: remote sensing, forest inventory updating, clearcut mapping, synthetic aperture radar, microwave, digital imagery

\section{Introduction}

Forest clearcut mapping is an important issue for Canadian forest partners (governments and industries). In 1995, clearcuts represented $85.7 \%$ of the total area harvested in Canada (Canadian Council of Forest Ministers 1996). Forest inventory updating is required by various forestry Acts of the different Canadian provinces (Hilton 1986, Gillis and Leckie 1996). This updating is mainly done using remote sensing tools. Up to now, forest clearcut mapping has been done mainly by photointerpreting 9" $\times 9$ " aerial photographs acquired at the scale of the inventory maps, varying from 1:10 000 in Nova Scotia, Ontario and Prince Edward Island to 1:20 000 in Quebec, Ontario, British Columbia and Alberta (Gillis and Leckie 1996). A promising alternative to these conventional aerial photographs would be provided by spaceborne sensors for two reasons. First, they can routinely provide lower-cost images in digital format that are easier to process and that allow the possibility of automating the mapping procedure. Second, fewer data are required, since spaceborne sensors cover a larger area.

Satellite images used for clearcut mapping were first provided by optical sensors (Leblon et al. 1995), for which data acquisition is limited because it depends on weather and illumination conditions. More recently, imaging radar spaceborne sensors, using synthetic aperture radars $(S A R)$, were developed (Table 1). They can acquire images, independent of these conditions, because they produce their own incident radiation that can penetrate clouds. In addition to the sensors on board of currently operated Earth's observation satellites (Table 1), there was an imaging radar sensor on board of SEASAT,

${ }^{1}$ Remote Sensing and GIS Research Group, Faculty of Forestry and Environmental Management, University of New Brunswick, Fredericton, NB EBB 6C2. Email: bleblon@unb.ca
La cartographie annuelle des coupes à blanc est actuellement faite au Canada à partir d'interprétation de photographies aériennes. Une alternative avantageuse utilise l'imagerie numérique. L'imagerie optique est dépendante des conditions climatiques et d'éclairement, mais pas l'imagerie radar. Cet articie décrit l'état de la pratique au Canada sur l'utilisation des images numériques radars pour la cartographie des coupes à blanc, notamment par rapport au type d'images utilisées, à l'influence des conditions environementales, de la bande spectrale, de la polarisation, du moment de l'année et de l'angle d'incidence, ainsi qu'à la précision cartographique. La synergie entre images optiques et radars est aussi discutée. Finalement, quelques systèmes expérimentaux de cartographie automatique à partir d'images radars sont présentés.

Mots-clés : Télédétection numérique, mise à jour de l'inventaire forestier, cartographie des coupes à blanc, radar à ouverture synthétique, micro-ondes, image numérique which was operational only from June to October 1978 (Buiten 1993). There were also radar sensors that were operated only during Shuttle missions, the last one (SIR-C/X$S A R$ ) being able to acquire multi-frequency and multi-polarization images (Table 2). This paper will document the state of understanding in Canada on applications of digital radar images acquired by spaceborne sensors to map forest clearcuts. Studies using airborne data will also be considered in this review, because of the lack of studies using radar satellite images, which have been provided more recently than the optical ones. Other Canadian examples on the use of imaging radar for clearcut mapping are also given in the review of Leckie and Ranson (1998).

\section{Factors Affecting the Clearcut Mapping on Radar Images}

Most of the experimental studies on the use of SAR images for clearcut mapping have used C-band airborne images in preparation to the RADARSAT mission. Some studies were carried out using airborne images acquired in X-, L- or P-band (Wedler et al. 1980; Rochon et al. 1986; Dams et al.1990; Ranson and Sun 1994, 1997; Ahern et al. 1995; Landry et al. 1996; Saatchi and Rignot 1997). Few studies have used spaceborne SAR L-HH images, like SEASAT images (Werle et al. 1986, Rochon et al. 1986) and SIR-B images (Drieman 1987). More recent studies tested images acquired with other spaceborne $S A R$, like the C-VV sensor on board the European satellite ERS1 (Cavayas et al. 1995, Schaller et al. 1995, Yatabe and Leckie 1995), the L-HH sensor on board the Japanese satellite JERS-1 (Schaller et al. 1995, Yatabe and Leckie 1995) as well as the S-HH sensor on board the Russian ALMAZ satellite (Yatabe and Leckie 1995). The most recent studies have used simulated (Rossignol and Ahern 1992; Banner and Ahern 1995a, 1996) or real (Ahern 1996, Ahern et al. 1997; Leckie 1997; Murtha 1997, 1998) images of the newest 


\begin{tabular}{|c|c|c|c|c|c|c|}
\hline Satellite & Spatial resolution & Time repetitivity & Band & Polarization & Incidence angle & Date of launch \\
\hline ERS-1 & $12.5-30 \mathrm{~m}$ & 35 days & $\mathrm{C}$ & VV & $23^{\circ}$ & 1991 \\
\hline$E R S-2$ & & & & & & 1995 \\
\hline ALMAZ-1 & $15-30 \mathrm{~m}$ & 5-7 days & $\mathrm{S}$ & $\mathrm{HH}$ & $30-60^{\circ}$ & 1991 \\
\hline JERS-1 & $18 \mathrm{~m}$ & \pm 1 month & $\mathrm{L}$ & $\mathrm{HH}$ & $38^{\circ}$ & 1992 \\
\hline RADARSAT & $9-100 m$ & 1 week -24 days & $\mathrm{C}$ & $\mathrm{HH}$ & $10-59^{\circ}$ & 1995 \\
\hline
\end{tabular}

Table 2. Temporary SAR satellites or missions (after Buiten 1993, Sardar 1997)

\begin{tabular}{lccccc}
\hline Sensor & Spatial resolution & Band & Polarization & Incidence angle & Operational period \\
\hline SEASAT & $25 \mathrm{~m}$ & $\mathrm{~L}$ & HH & $20^{\circ}$ & June-Oct. 1978 \\
SIR-A & $40 \mathrm{~m}$ & $\mathrm{~L}$ & HH & $47^{\circ}$ & Nov. 1981 \\
SIR-B & $17-58 \mathrm{~m}$ & $\mathrm{~L}$ & HH & $15-60^{\circ}$ & Oct. 1984 \\
SIR-C/X-SAR & $10-60 \mathrm{~m}$ & $\mathrm{C}$ & All four & $15-60^{\circ}$ & April 1994 \\
& & L & All four & Sept. 1994 \\
\end{tabular}

(1) Multi-polarization and multi-frequency SAR

Canadian radar satellite, RADARSAT. There are also some studies using the $S I R-C / X-S A R$ prototype, which produces $\mathrm{X}$ VV and multi-polarized C and L-band images (Ranson $\mathrm{et}$ al. 1995, Ranson and Sun 1997).

As in the case of optical sensors (Leblon et al. 1995), most clearcut mapping was done using summer images. However, clearcut mapping is more accurate when winter images are included together in the analysis (Drieman et al. 1989a; Ahern et al. 1993a, b; Drieman 1994; Yatabe and Leckie 1995). Indeed, snow cover and frozen soil have a dielectric constant which is low enough to reduce the backscatter of open areas (Ahern et al. 1993a), probably because of the low dielectric constants of frozen or near freezing targets (Way et al. 1990). Another important environmental factor is the moisture either atmospheric (rainfall or snowfall), surface moisture on vegetation or ground moisture - conditions which tend to reduce the contrast between forest and clearcuts on a C-band airborne multi-temporal image (Drieman et al. 1989a) and on an August ERS-1 image (Yatabe and Leckie 1995). For this reason, dry summer weather was shown to be one of the best environmental conditions to discriminate clearcuts from surrounding forests on ERS-1 images (Yatabe and Leckie 1995) and on RADARSAT images (Leckie 1997). However, more recently, wet snow was shown to be a better environmental condition to increase the contrast between clearcuts and surrounding forests (Ahern et al. 1997, Leckie 1997). Also, when there is no snow on the ground, RADARSAT winter images acquired on Pacific rain forests are useful to map recent clearcuts (Murtha 1997, 1998a). On these images, contrast between clearcuts and forests decreases when clearcuts dried out (Murtha 1998). The influence of environmental conditions during acquisition is more important in the case of C-band than for L- or S-band (Schaller et al. 1995, Yatabe and Leckie 1995, Leckie 1997). This environmental influence explains why the use of multi-temporal images acquired during contrasting seasons improved the clearcut identification on SAR images (Fig. 1) (Drieman et al.1989a, Ahern et al.1993a, Ranson and Sun 1994, Schaller et al. 1995, Ranson and Sun 1997, Murtha 1998).

Determining the best band/polarization combination for clearcut mapping is highly important because, unlike spaceborne optical sensors (Leblon et al. 1995), current satellite SAR sen- sors work only in a single waveband and in a single polarization (Ahern et al. 1993c), although planned SAR sensors like the $S I R-C / X-S A R$ prototype will work in a multi-polarization and multi-band manner (Sardar 1997). For C-band images, crosspolarized data $(\mathrm{HV}, \mathrm{VH})$ are more suitable than like-polarized data (VV, HH) (Leckie 1984, Drieman et al. 1989b, Werle 1989, Leckie 1990, Ahern et al. 1995, Landry et al. 1996) (Fig. 2). Also, a better map is obtained using composites of images having different polarizations and/or different bands (Leckie 1990, Ranson and Sun 1994, Ahern et al. 1995, Ranson et al. 1995, Landry et al. 1996, Ranson and Sun 1997, Saatchi and Rignot 1997). Similar to other open areas like agricultural fields, clearcuts are better discriminated from the surrounding forests on images acquired in long wave bands (L-or P-band) (Fig. 3) (Drieman 1987, Werle 1989, Koch et al. 1992, Ahern et al. 1995, Schaller et al. 1995, Yatabe and Leckie 1995, Landry et al. 1996). However, P-band is too sensitive to small holes in the forest canopy, which can lead to highly fragmented images after classification (Ahern et al.1995, Landry et al.1996). The bad separability on C-band images between open and forested areas is due to the wide range and variability of radar backscatter from open areas (Ahern et al.1993a, Mancilla et al.1995), as well as to an overlap of radar backscatter with surrounding forests (Leckie 1984, Ahern and Drieman 1988, Ahern et al.1993a, Yatabe and Leckie 1995). Also, short-wave bands are more strongly influenced by fine canopy elements such as leaves, needles and small branches as well as by grass and shrubs on the ground (Yatabe and Leckie 1995). For this reason, leafless hardwoods have a radar return similar to conifer stands on ERS- $I \mathrm{C}-\mathrm{VV}$ images, and thus discrimination between leafless hardwoods and clearcuts is possible on such images (Cavayas et al.1995).

Regeneration, which tends to mask clearcut boundaries (Drieman 1987, Mancilla et al.1995), is better assessed using L-band images (Wedler et al. 1980, Ahern et al. 1995, Landry et al. 1996) rather than using shorter-wavelength images. For C-band images, $\mathrm{HH}$ polarization is more sensitive to regeneration than VV polarization (Mancilla et al. 1995). Multi-polarization images were shown to outperform single polarization images in distinguishing regeneration classes (Ahern et al. 1995, Landry et al. 1996). As for clearcuts, regeneration areas were better classified using multi-polarized, multi-frequency and/or multi- 

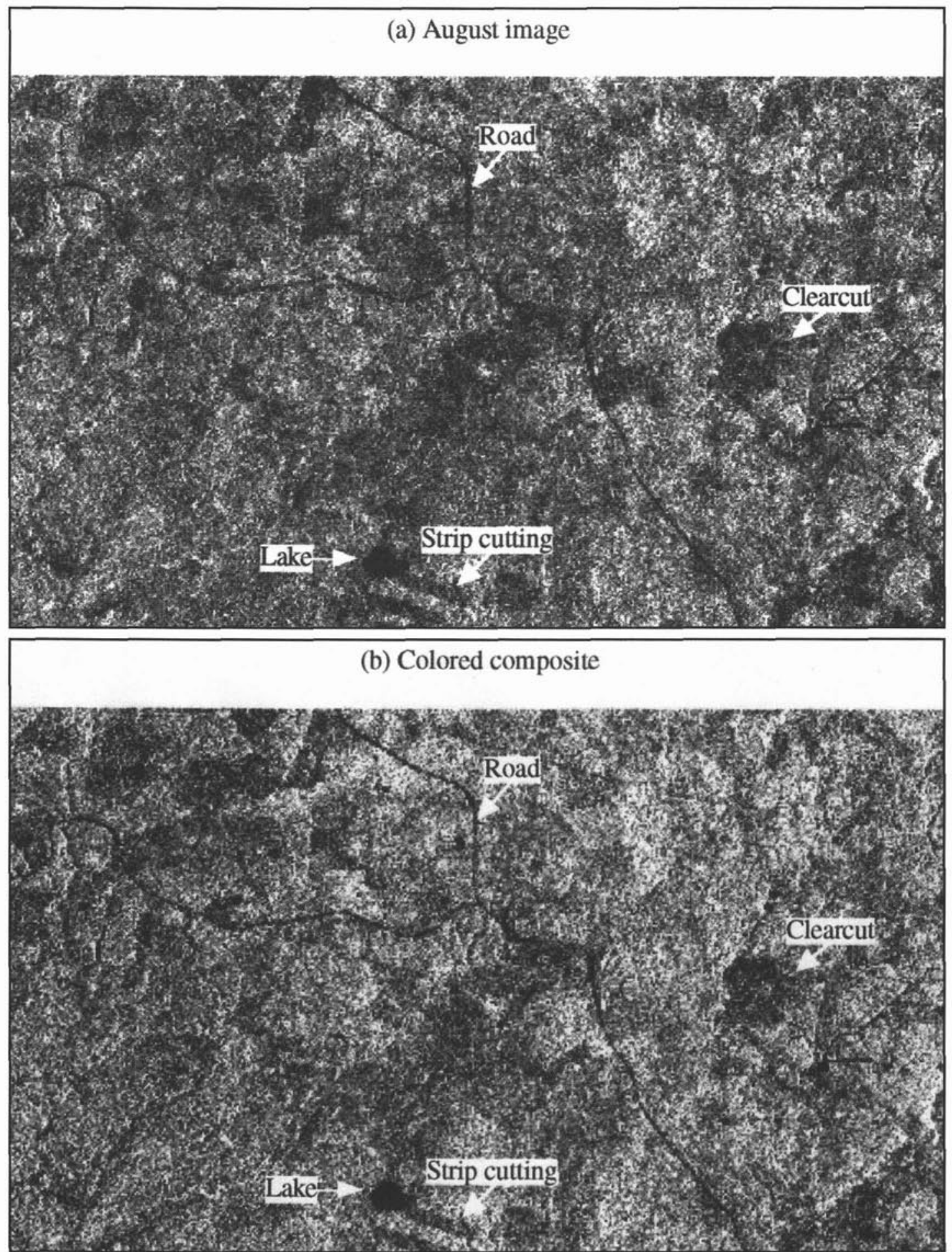

Fig. 1. Single-date image acquired in August and colour composite made from February (red gun), August (blue gun) and October (green gun) images, in the case of JERS-1 images acquired in 1993 and on the same harvested area near Whitecourt, Alberta.

temporal images (Ranson and Sun 1994, 1997). The better Lband performance for clearcut mapping and regeneration assessment is due to the higher penetration of the ground vegetation in the cuts, resulting in low backscatter for recent clearcuts and increasing backscatter with vegetation density and, therefore, high cut-background contrast (Yatabe and Leckie 1995). Also, longer-wavelength bands are less sensitive to the fine canopy elements than to the dominant branches, to the trunks and to the double bounce interaction between trunk and soil (Richards et al. 1987, Yatabe and Leckie 1995, Landry et al. 1996).

Similar to optical images (Leblon et al. 1995), clearcuts on radar images can be confused with open areas, like agricultural fields and wetlands. These open areas can be masked when using a geographical information system database. Another solution would be to try to discriminate them from the 

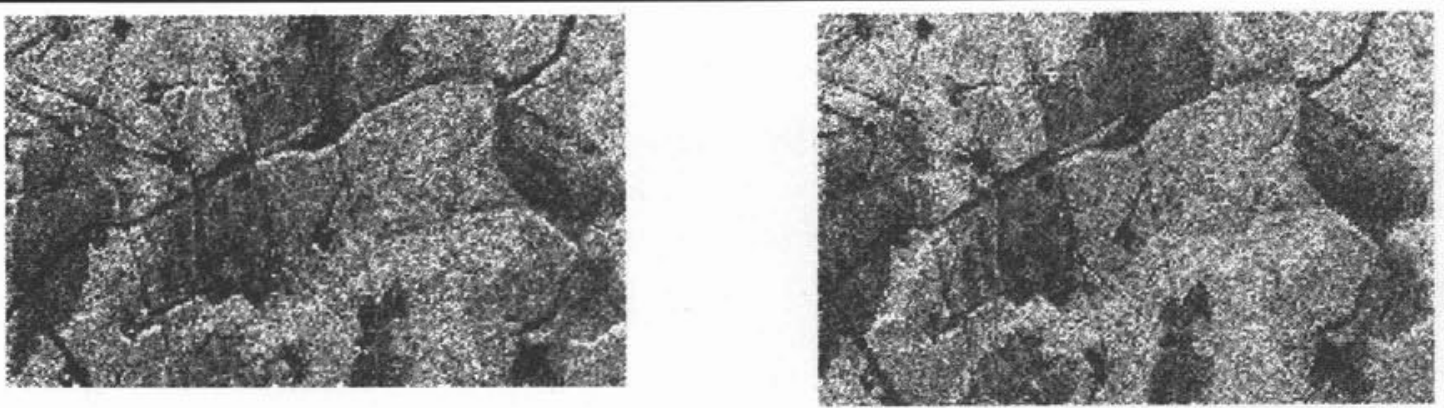

(a) $\mathrm{HH}$ polarization

(b) VV polarization

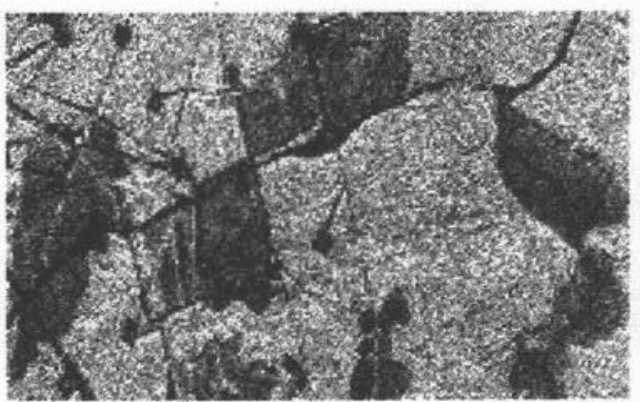

(c) HV polarization

Fig. 2. Comparison between C-band SAR images acquired with the JPL-AIRSAR in three polarization modes (HH, VV and HV), on the same harvested area near Whitecourt, Alberta, in May 1991.

clearcuts. Yatabe and Leckie (1995) showed that grasslands are discriminated from clearcuts on ERS-1 or JERS-1 images acquired in July during dry conditions, because grasslands have a lower backscatter than clearcuts. Clearcut backscatter is increased with the ground vegetation density. Clearcuts and wetlands are better separated on L-band images than on shorter-wavelength images (Ahern et al. 1995, Yatabe and Leckie 1995, Landry et al. 1996), possibly because the higher vegetation density on wetlands than on clearcuts results in a greater penetration and a lower return of C-band waves from the clearcuts than from the wetlands.

Unlike optical sensors (except the SPOT satellite sensor), $S A R$ sensors have the capability of acquiring data in different incidence angles (Ahern et al. 1993c). This factor has probably the most important influence on the contrast between clearcuts and surrounding forests. Contrast increases with the incidence angle (Fig. 4) (Banner and Ahern 1995b). The incidence angle must be at least $30^{\circ}$ to allow clearcut identification on SAR images (Werle et al. 1986, Rossignol and Ahern 1992). Incidence angles of ERS-1 $\left(23^{\circ}\right)$ and of SEASAT $\left(20^{\circ}-26^{\circ}\right)$ are therefore insufficient for discriminating clearcuts (Werle etal. 1986, Rossignol and Ahern 1992, Ahern and Raney 1993, Schaller et al. 1995, Yatabe and Leckie 1995). By contrast, clearcuts were well identified on a SIR-B L-HH image acquired with an incidence angle of $59^{\circ}$ (Drieman 1987). On C-HH airborne images, contrast between clearcut and surrounding mixed boreal forests is greater than $2: 1(3 \mathrm{~dB})$ for incidence angles greater than $60^{\circ}$ (Banner and Ahern 1995b). The better contrast between clearcut and surrounding forests on simulated (Rossignol and Ahern 1992, Banner and Ahern 1995a) or real (Ahern 1996) RADARSAT C-HH images is also explained by the higher incidence angle $\left(47^{\circ}\right)$ of the RADARSAT sensor compared to the ERS-1 system.

The effect of incidence angle on clearcut visibility depends on the topography of the area, and local incidence angles as defined in Foody (1986) must be considered in the case of rugged terrain. Slope effects on radar backscatters are such that clearcut visibility can be greatly reduced on slopes facing towards the radar illumination (Drieman 1987, Ahern et al. 1997). These effects are stronger on images acquired using a steep incidence angle, like with the ERS- 1 satellite, and for the coherent component of the scattering than for its diffuse component (Ahern and Raney 1993). They are also more important on images acquired in short-wave bands, like the X-band (Werle et al. 1986) or the C-band of ERS-1 (Cavayas et al. 1995, Schaller et al. 1995, Yatabe and Leckie 1995). The relationship between backscatter and local incidence angle does not depend only on the topography, but also on the cover type (Hinse et al. 1988, Warner et al. 1996).

Another factor of variability on $S A R$ images is the speckle, which gives the typical grainy appearance of SAR images. The speckle effect can be reduced by different image pre-processing techniques, for example principal component analysis (Ahern et al. 1993b) or spatial filtering (Koch et al. 1992, Yatabe and Leckie 1995), although Banner and Ahern (1996) showed that spatial filtering does not improve the clearcut bound- 

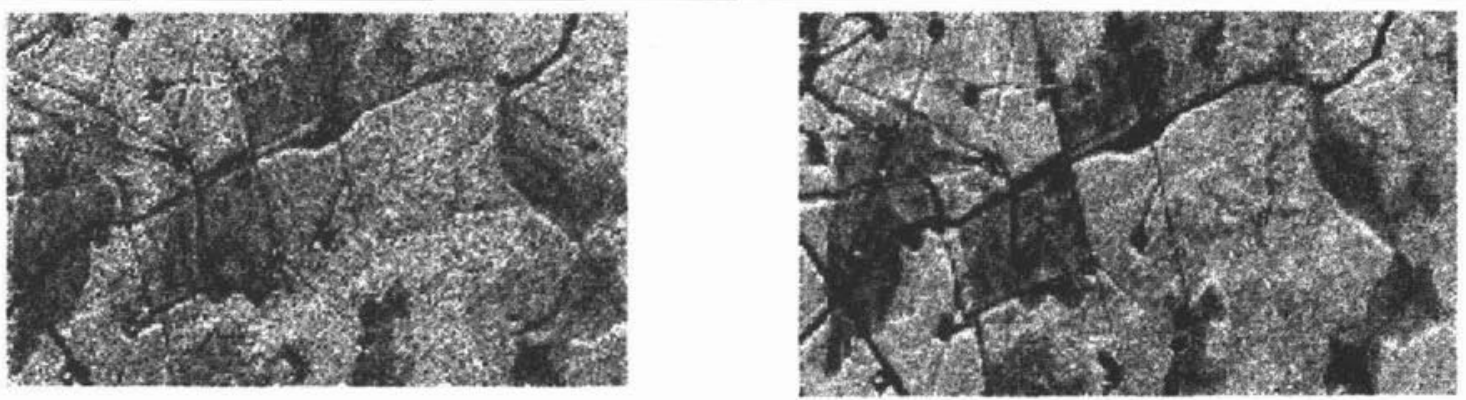

(a) C-band

(b) L-band

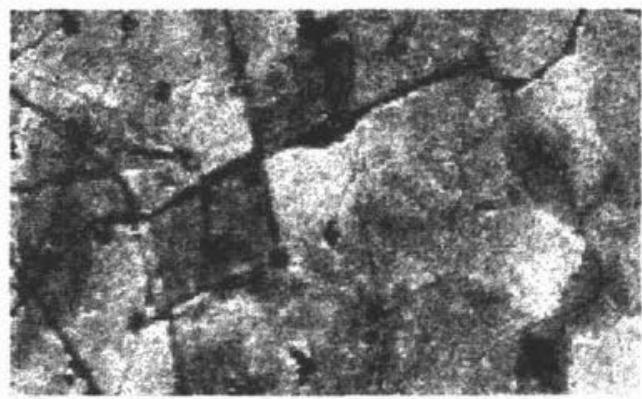

(c) P-band

Fig. 3. Comparison between HH-polarized SAR images acquired with the JPL-AIRSAR in three bands (C, L and $\mathrm{P})$, on the same harvested area near Whitecourt, Alberta, in May 1991.

ary mapping accuracy when visual interpretation is used to delineate boundaries.

Compared to optical images, less elaborate analysis methods have been used on radar images, because of the general poorer clearcut visibility on radar images (Leblon et al. 1995). Most clearcut mapping was performed by visual interpretation of raw or digitally enhanced images. Enhancements significantly improved mapping results. Some statistical parameters were also employed to assess clearcut separability from other forest cover type classes, such as the JeffreysMatusita distance (Ahern et al. 1993a, Yatabe and Leckie 1995). Rochon et al. (1986) applied the maximum-likelihood classifier on a pixel-by-pixel basis to classify forest cover types (including clearcuts) on an airborne $S A R \mathrm{X}-\mathrm{HH}$ and on a SEASATL-HH image, both being acquired over temperate conifer rain forests. In both cases, the percentage of correctly classified pixels was low. Indeed, good classification accuracy supposes a unique radar return from the class, which must, in addition, be distinct from the radar return of the other classes (Leckie 1984). Both criteria are not met in most of cases. For example, at least on C-band images, clearcuts have been shown to have variable radar return (Drieman 1987, Ahern et al. 1993a, Mancilla et al. 1995, Yatabe and Leckie 1995), because of the variability effects of moisture and temperature conditions (Drieman et al. 1989a, Way et al. 1990, Yatabe and Leckie 1995, Ahern et al. 1997, Leckie 1997), ground vegetation density (Drieman 1987, Yatabe and Leckie 1995), surface material (Yatabe and Leckie 1995, Murtha 1998) or incidence angle
(Wedler et al. 1980). All these factors can also lead to radar backscatter overlapping between clearcuts and surrounding forests (Leckie 1984, Drieman 1987, Ahern and Drieman 1988, Ahern et al. 1993a, Yatabe and Leckie 1995, Murtha 1998).

\section{Synergism Between Optical and Radar Images}

Advantages of combining optical and radar data were investigated in few studies. Indeed, optical imagery provided excellent spectral and interpretative information (including vegetation competition in plantations), while radar imagery provided good edge definition of delineating boundaries and good portrayal of relief (Baker 1992). Drieman (1987) combined a SIR-B L-HH image with a LANDSAT-TM image (all optical bands). The first image was acquired in October and the second, in the summer following the $S I R$ - $B$ overpass. He concluded that the addition of SIR-B to the TM data set did little to improve class separabilities as calculated using TM alone. Leckie (1990) combined airborne multi-polarization X-and C-band SAR images with visible/infrared airborne $M S S$ data acquired in the same time. Open areas best differentiated from forest classes in the visible and in the mid-infrared. The near-infrared bands were best for discriminating open areas of different vegetation densities. Adding X-VV and C-HH data little improved class separabilities, both bands, however, being highly useful for forest species discrimination. For mapping forest clearcuts on 1:50000 maps of woodlots, Baker (1992) used two methods to combine one 30m-resolution 


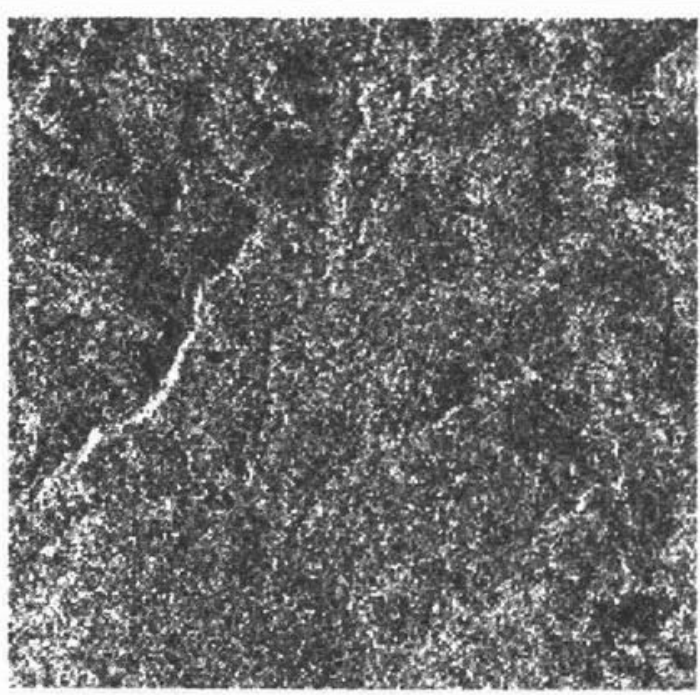

(a) Incidence angle of $20-27^{\circ}$

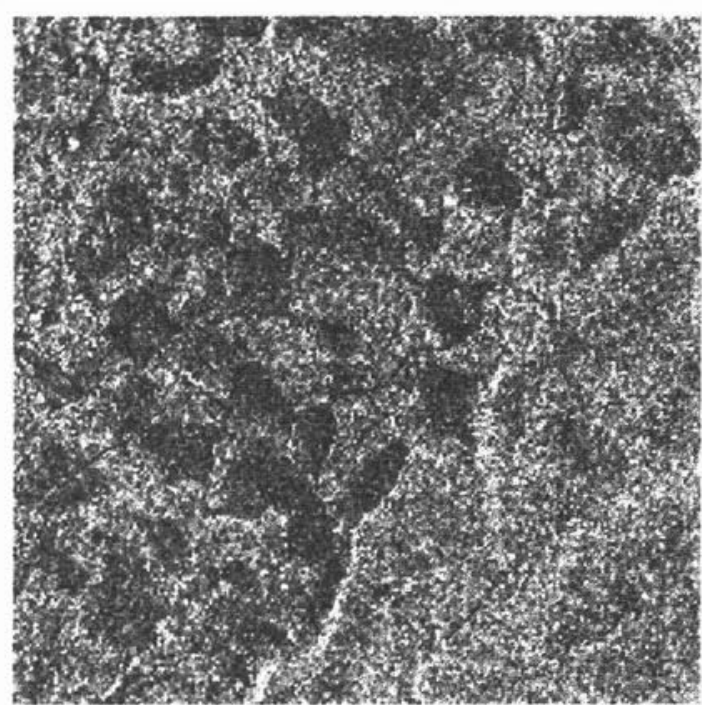

(b) Incidence angle of $45-49^{\circ}$

Fig. 4. RADARSAT (C-HH band) images acquired in winter 1996 on the same harvested area near Whitecourt, Alberta, with two incidence angles.

LANDSAT-TM (band 4, 5, and 7) image acquired in June with one airborne $15 \mathrm{~m}$-resolution radar image acquired in April. The first method is an intensity, hue and saturation (IHS) method that produces images with good colour quality. The second one is an arithmetic procedure in which each red, green, blue (RGB) channel results from an arithmetic combination on TM and radar bands. The IHS method produced images, where a part of the clearcut area was obscured by radar shadow. However, in both cases, clearcuts cannot be automatically mapped from the digital image and on-screen visual digitizing of the image put as backdrop is required. Finally, Rossignol and Ahern (1992) showed that a simulated RADARSAT image can be used as complementary to a LANDSAT-TM image to monitor forest changes, once the $L A N D S A T-T M$ image is registered to the SAR image to permit the overlay of both scenes.

\section{Accuracy Considerations}

Table 3 compares literature results for clearcut mapping accuracies. All the reported studies refer to the same logging area in Alberta, except Drieman (1994), who studied logging areas in Newfoundland. Also, all of them refer to C-HH images, except Dams et al. (1990), who used X-HH images. Clearcut mapping accuracies in Table 3 were assessed using the following criteria:

(i) the areal percentage accuracy, calculated as:

$\%$ accuracy $=100 \%$-(Image-derived area - Actual area)

Actual area

(Hall et al. 1989)

(ii) the boundary mapping error, calculated following the method of Archibald and Ahern (1985). This method uses twelve vectors about the mean centroid, vectors pointing towards (away from) the centre having a negative (positive) direction. For the $\mathrm{j}^{\text {th }}$ clearcut polygon, two variables can be estimated from its arbitrary centroid, as measure of the boundary mapping error: a) $D_{j}$ which is the average of the absolute values of the $12 \mathrm{vec}-$ tor lengths $\mathrm{D}_{i}$ :

$$
D_{j}=\frac{1}{12} \sum_{i=1}^{12}\left|D_{i}\right|_{0}
$$

where $D_{i}=\sqrt{\left(x_{i 2}-x_{i 1}\right)^{2}+\left(y_{i 2}-y_{i 1}\right)^{2}}$. length of the vector in the $\mathrm{i}^{\text {th }}$ direction

$\left(\mathrm{x}_{\mathrm{i} 1}, \mathrm{y}_{\mathrm{i} 1}\right)=$ coordinates of the intersection between the $\mathrm{i}^{\text {th }}$ direction and the actual boundary

$\left(\mathrm{x}_{\mathrm{i} 2}, \mathrm{y}_{\mathrm{i} 2}\right)=$ coordinates of the intersection between the $\mathrm{i}^{\text {th }}$ direction and the image-derived boundary.

b) $\mathrm{RMS}_{\overparen{d}}$ which is the standard deviation of the 12 vector lengths:

$$
R M S_{d}=\sqrt{\frac{1}{12} \sum_{i=1}^{12} D_{i}^{2}}
$$

Values reported in Table 3 as boundary-mapping errors are the mean value for all the clearcut polygons considered of either $\mathrm{D}_{\mathrm{j}}$ (Ahern and Drieman 1988, Dams et al. 1990) or RMS (Ahern and Drieman 1988, Banner and Ahern 1995a, Ahern et al. 1997). Archibald and Ahern (1985)'s method can be used only in the case of regular-shaped clearcuts with relatively small differences between actual and image-derived boundaries. In the case of irregular-shaped clearcuts with large differences between actual and image-derived boundaries, it is preferable to use a generalization of the method of Archibald and Ahern (1985), developed by Edwards and Rioux (1995), because under this method, all directions are considered instead of only the twelve directions. 
Table 3. Comparison between literature results for clearcut mapping accuracy on SAR images

\begin{tabular}{|c|c|c|c|c|c|}
\hline Sensor & $\begin{array}{l}\text { Spatial } \\
\text { resolution }\end{array}$ & $\begin{array}{c}\text { Minimum } \\
\text { clearcut } \\
\text { size (in ha) }\end{array}$ & $\begin{array}{c}\text { Areal } \\
\text { accuracy } \\
\text { (in \%) }\end{array}$ & $\begin{array}{l}\text { Boundary } \\
\text { mapping error } \\
(\text { in } \mathbf{m})^{(\mathbf{1})}\end{array}$ & Authors \\
\hline $\begin{array}{l}\text { Airborne } \\
\text { (X-HH band) }\end{array}$ & $6-12 m$ & 0.7 & 89.8 & $29.4^{(*)}$ & Dams et al. (1990) \\
\hline $\begin{array}{l}\text { Airborne } \\
\text { (C-HH band) }\end{array}$ & $6-12 m$ & 5.0 & 89.0 & $30.0^{(*)}$ & 43.0 Ahern and Drieman (1988) \\
\hline $\begin{array}{l}\text { Airborne } \\
\text { (C-HH band) }\end{array}$ & $6-12 m$ & 1.3 & 89.3 & $\mathrm{n} / \mathrm{a}$ & Drieman (1994) \\
\hline $\begin{array}{l}\text { Airborne } \\
\text { (C-HH band) }\end{array}$ & $6-12 m$ & $\mathrm{n} / \mathrm{a}$ & 92.0 & 24.6 & Banner and Ahern (1995a) \\
\hline $\begin{array}{l}\text { Simulated } R A D A R S A T \\
\text { (C-HH band, fine-mode) }\end{array}$ & $10 \mathrm{~m}$ & $\mathrm{n} / \mathrm{a}$ & 84.0 & 44.9 & Banner and Ahern (1995a) \\
\hline $\begin{array}{l}\text { Simulated RADARSAT } \\
\text { (C-HH band, standard-mode) }\end{array}$ & $25 \mathrm{~m}$ & $\mathrm{n} / \mathrm{a}$ & 71.0 & 72.7 & Banner and Ahern (1995a) \\
\hline $\begin{array}{l}\text { RADARSAT } \\
\text { (C-HH band, fine-mode) }\end{array}$ & $9-10 m$ & $\begin{array}{l}\text { Contrast: } \\
\text { - high } \\
\text { - medium } \\
\text { - low }\end{array}$ & $\begin{array}{l}\mathrm{n} / \mathrm{a} \\
\mathrm{n} / \mathrm{a} \\
\mathrm{n} / \mathrm{a}\end{array}$ & $\begin{array}{l}21.6 \\
40.6 \\
69.6\end{array}$ & Ahern et al.(1997) \\
\hline
\end{tabular}

(1) The boundary mapping error is calculated according to Eq. 2, for the studies with asterisks and according to Eq. 3, for the other studies.

Table 3 shows that fine mode RADARSAT images gave a better mapping accuracy than standard mode images, thanks to the higher spatial resolution of the first type of images. In the case of optical images, Leblon et al. (1995) already showed that the spatial resolution of optical sensors is a key parameter for clearcut-mapping accuracy. Also, as reported above, clearcut-mapping accuracy is affected by the contrast between clearcuts and surrounding forests. For example, the boundary-mapping error decreases when this contrast increases in the case of fine-mode RADARSAT images like those used in Ahern et al. (1997) (Table 3). This contrast depends on the environmental conditions at the time of image acquisition. For example, in Ahern et al. (1997), high-contrast images were acquired under wet snow conditions. For the studies using airborne images, the best mapping accuracy, which was achieved in Banner and Ahern (1995a), was also obtained on winter images with snow, whereas the worst mapping accuracy was obtained by Ahern and Drieman (1988), who used fall images. Leckie (1997), Ahern et al. (1997) and Murtha (1998) already concluded that clearcut visibility on RADARSAT images depends primarily on surface moisture conditions.

Clearcut boundaries are more complex to define on radar images than on optical images, because they differ as a function of the radar illumination direction. According to Murtha (1997), four kinds of boundaries can be defined: bright boundary when at right or oblique angles (facing) to radar illumination, shadowed boundary facing away from the illumination, and two boundaries parallel to the illumination. The two last boundaries were found to be difficult to see on a fall airborne C-HH image acquired on Alberta boreal forests (Ahern and Drieman 1988) as well as on a winter wet evening fine-mode RADARSAT image acquired on British Columbia rain forests (Murtha 1997). In this case, these boundaries must be located by comparison to adjacent uncut forests (Murtha 1997). The boundary facing the illumination can be very bright, because of the corner reflection effect made by straight edges (Ahern and Drieman 1988, Murtha' ${ }^{2}$. As for the shadowed boundary,

${ }^{2}$ Personal communication. E-mail 23/06/98. for such a bright boundary, the true cut edge is difficult to estimate on the airborne $\mathrm{C}$-HH image used by Ahern and Drieman (1988), but not on a fall SIR-B L-HH image acquired on Alberta boreal forests (Drieman 1987) nor, according to Murtha $^{2}$, on the fine-mode RADARSAT image used by Murtha (1997). Shadowed and bright boundaries also allowed older clearcuts to be distinguished on a RADARSAT image simulated with airborne data acquired in March (Rossignol and Ahern 1992).

Apart from the mapping error related to the radar imagery itself, another possible source of boundary mapping errors is related to the accuracy of the reference map. For example, the required minimal boundary mapping error of $20 \mathrm{~m}$ (Gillis and Leckie 1996) represents $1 \mathrm{~mm}$ on a 1:20000 scale map. Such a scale is small enough to contribute to mapping errors through plotting errors and pen line widths (Hall et al. 1989). Furthermore, in most of mapping accuracy analysis, maps derived from ground-truth are compared within a geographic information system to maps derived from satellite images. However, Edwards (1993) pointed out that the main problem in this procedure is the different nature of the compared maps: the satellite-derived map is a thematic map, that results from physical (electromagnetic radiation) measurements of the reality, whereas the ground truth-derived map is a representation and a simplification of the reality. The problem could be more significant, if both maps have a different scale (Lee et al. 1993).

\section{Automated Processing of Radar Digital Imagery}

Because the visibility of clearcuts on SAR imagery is poorer than on optical imagery, only a small number of automated systems to process such images has been developed. For example, Edwards and Beaulieu (1989) applied, on SAR imagery containing forest clearcuts, a segmentation algorithm called the Hierachical Step-Wise Optimization (HSWO) algorithm (Beaulieu and Goldberg 1989). The method requires this algorithm be applied twice: first, on the original unfiltered image resulting in very large segments that are actually networks of smaller segments joined by "noise bridges" and second, on the heavily filtered image, on which compact regions 
are identified as clearcut cores, but giving a very poor estimate of the clearcut boundary. By overlaying the two segmented images, segments can be regrouped into distinct clearcuts with relatively precise boundaries. However, this method requires a large processing time and often a semi-automated procedure is applied using visual correction of the image resulting from the overlaying of the two segmented images (Edwards and Rioux 1995). More recently, for detecting clearcuts on a ERS-1 image acquired during leafless conditions (beginning of May) on typical mixed boreal forests in Quebec, Cavayas et al. (1995) proposed an automated system which classifies the polygon as clearcut, if for the corresponding polygon, the histogram describing the distribution of digital numbers (translated into an 8-bit grey level scale) is unimodal and has its mode being less than 6 and its entropy being less than 3 . The polygon corresponding to a partial cut has a bimodal distribution with a mode of less than 6 . This system gave a better classification accuracy for clearcut polygons than for partial cut polygons. However, as for the previous automated systems using optical images (see the review in Leblon et al. 1995), the empirical definition of threshold values limits the operational use of the system.

\section{Conclusions}

The literature review presented here has shown that the use of radar images for clearcut mapping is still under experimental study, although radar sensors have the advantage of being independent of weather and illumination conditions. Our review has shown that clearcut mapping is more accurate using multi-date images acquired during contrasting seasons of the year. This mapping was also shown to be more accurate on images acquired in longer wavelengths and in cross-polarized mode as well as in multi-frequency and multi-polarization images. Thus, the planned spaceborne $S A R$ sensors, like the $S A R$ sensor on the Earth Observing System (EOS) and the Advanced SAR (ASAR) on ENVISAT (Sardar 1997) as well as, later on, RADARSAT-2 (CCRS 1998), will have the possibility of simultaneously acquiring data indifferent polarizations, including the cross-polarization. The latter two will acquire data only in the $\mathrm{C}$-band, but the first one will have the additional advantage of simultaneously acquiring data in different frequencies (Sardar 1997). A key parameter of clearcut visibility on SAR images is the contrast between clearcuts and surrounding forests. This contrast is highly dependent on environmental conditions, particularly for C-band images, as well as on incidence angle. As with the most recent spaceborne $S A R$, RADARSAT (Table 1), future $S A R$ will acquire data in a variety of incidence angles, from $15^{\circ}$ to $45^{\circ}$ in the case of $E O S$ SAR and ENVISAT-ASAR, (Sardar 1997).

Clearcut mapping accuracy is highly dependent on the spatial resolution of the image. Currently, RADARSAThas the capability of producing images with the highest spatial resolution (9-10 m) (Table 1). Among all the planned SAR sensors, RADARSAT-2 is the one that will acquire images having a significantly higher spatial resolution ( $3 \mathrm{~m})$. As for the current $S A R$ images, there will be an increasing interest in using not only the spectral dynamic of the image, but also its spatial dynamic through so-called texture analysis, which is more suitable on high spatial resolution images. However, further research is required to evaluate the usefulness of textural analysis for clearcut mapping.
Despite the potential value of current spaceborne radar images, its operational use for clearcut mapping is limited by the poor visibility of clearcuts on the image. Operational use of radar images must also be assessed in terms of cost-effectiveness. In this assessment, one may not only consider the cost per hectare of image acquisition, but also other cost-related factors. Indeed, the use of digital imagery could be expensive, if clearcuts are not spatially concentrated on a single digital image. In addition, harvest operation methods are now changing, from total to partial harvest. Partial cuts will then be more difficult to map because of the remaining vegetation (trees, shrubs, etc.), which can lead to confusion with surrounding forests. However, uncut forest strips within clearcuts, like riparian zone leave strips, are detectable on fine-mode RADARSAT images acquired during wet conditions, particularly if they are undamaged and newly created (Murtha 1997, Murtha and Mitchell 1998). On such images, stumps and logging debris within the cuts makes clearcuts brighter than surrounding forests (Murtha 1997, 1998). Also, alternating strips of cuts and forests are visible on a fall SIR-B L-HH image (Drieman 1987) and on JERS L-HH images (Fig. 1). Finally, forest inventory updating from radar images is a challenge, not only for Canadian forests, but also for tropical forests, where forest depletions have dramatically increased in the past few years (Lee et al. 1993) and where clear days are more rare than at Canadian latitudes.

\section{Acknowledgements}

The author thanks F. Ahern who carefully revised the manuscript and kindly gave all the SAR images used in the paper. Many thanks also to G. Jordan, Faculty of Forestry and Environmental Management, to R. Landry, Canada Centre of Remote Sensing, to I. McKirdy, Dendron Resource Surveys Ltd and to two anonymous reviewers. There was also a technical contribution of A. Sood. The study was funded by the Canada/New Brunswick Cooperation Agreement on Forest Development, the NSERC/industrial partnership program and by the British Columbia Ministry of Forests.

\section{References}

Ahern, F.J. 1996. Clear-cut at last! In Remote Sensing in Canada, Natural Resources Canada, Ottawa, Ontario. 24(1): 4.

Ahern, F.J. and J.A. Drieman. 1988. Assessment of clearcut mapping accuracy with C-band SAR. In Proc. of the Int. Geoscience and Remote Sensing (IGARSS'88) Symp., September 1988, Edinburgh, Scotland, UK. pp. 1335-1338.

Ahern, F.J. and R.K. Raney. 1993. An ALMAZ/ERS-1 comparison demonstrates incidence angle effects in orbital SAR imagery. Can. J. Remote Sens. 19(3): 259-262.

Ahern, F.J., D.G. Leckie and J.A. Drieman. 1993a. Seasonal changes in relative C-band backscatter of Northern forest cover types. IEEE Trans. Geosc. Remote Sens., 31(3): 668-680.

Ahern F.J., J. Brown, I. McKirdy and B. Titley. 1993b. The information content of multi-polarized, multi-season C-SAR data of the Boreal Forest: a preliminary assessment. In Proc. of the 16th Canadian Symp. on Remote Sensing and 8th Symp. of AQT, June 1993, Sherbrooke, Québec. pp. 387-392.

Ahern, F.J., D.G. Leckie and D. Werle. 1993c. Applications of RADARSAT SAR data in forested environments. Can. J. Remote Sens. 19(4): 330-337.

Ahern, F.J., R. Landry, S. Paterson, D. Boucher and I. McKirdy. 1995. Forest landcover information content of multi-frequency multi-polarized SAR data of a boreal forest. In Proc. of the 17th Canadian 
Symp. on Remote Sensing, June 1995, Saskatoon, Saskatchewan. pp. 537-549.

Ahern, F.J., R. Landry, S. Paterson, I. McKirdy, V. Janusauskas, A. Banner, J. Russell and T. Balce. 1997. Factors affecting clearcut mapping accuracy from single-date RADARSAT images. In Proc. of the 19th Canadian Symp. on Remote Sensing, May 1997, Ottawa, Ontario. Available on CD-ROM.

Archibald, P.D. and F.J. Ahern. 1985. A statistical analysis of forest harvest depletion mapping using Landsat-MSS data. In Proc. of the 19th Int. Symp. on Remote Sens. of Environ., Ann Arbor, MI, USA.pp. 697-709.

Baker, A.B. 1992. Integration of Landsat-TM and airborne radar data into an operational GIS for forest inventory applications. In Proc. of the 15th Canadian Symp. on Remote Sensing, June 1992, Toronto, Ontario. 4 p.

Banner, A.V. and F.J. Ahern. 1995a. Forest clearcut mapping using airborne C-band SAR and simulated RADARSAT imagery. Can. J. Remote Sens. 21(2): 124-137.

Banner, A.V. and F.J. Ahern. 1995b. Incidence angle effects on the interpretability of forest clearcuts using airborne C-HH SAR imagery. Can. J. Remote Sens. 21(1): 64-66.

Banner, A.V. and F.J. Ahern. 1996. Spatial filtering of simulated fine-mode RADARSAT imagery for clearcut mapping. In Proc. of the 26th Int. Symp. on Remote Sensing of Environment and 18th Canadian Symp. on Remote Sensing, March 1996, Vancouver, British Columbia. pp. 343-348.

Beaulieu, J.M. and M. Goldberg. 1989. Hierarchy in picture segmentation: a stepwise optimization approach. IEEE Trans. Geosc. Remote Sens. 11(2): 150-163.

Buiten, H.J. 1993. Specifications of some microwave satellite systems and nomenclature of radar frequency bands. In H.J. Buiten and J.G.P.W. Clevers. Land observation by remote sensing: Theory and applications. Current Topics in Remote Sensing, Volume 3. pp. 539-549. Gordon and Breach Science Pub., Colorado.

CCRS. 1998. RADARSAT-2: high resolution, multi-polarization. In Remote Sensing in Canada, Natural Resources Canada, Ottawa, Ontario. 26(1): 1

Canadian Council of Forest Ministers. 1996. Compendium of Canadian Forestry Statistics 1995. Ottawa, Ontario. 202 p.

Cavayas, F., M. Beaulieu and R. Desjardins. 1995. Mise à jour des cartes forestières à l'aide des images satellites: l'apport de l'imagerie ERS-1. In Proc. of the Int. Symp. "Retrieval of bio- and geophysical parameters from SAR data for land applications," October 1995, Toulouse, France. pp. 179-183.

Dams, R.V., R.J. Hall and F.J. Ahern 1990. Forest clearcut mapping from X-band SAR. Can. J. Remote Sens. 16(2): 1-7.

Drieman, J.A. 1987. Evaluation of SIR-B imagery for monitoring forest depletion and regeneration in Western Alberta. Can. J. Remote Sens. 13(1): 19-25.

Drieman, J.A. 1994. Forest cover typing and clearcut mapping in Newfoundland with C-band SAR. Can. J. Remote Sens. 20(1): 11-16.

Drieman, J.A., D.G. Leckie and F.J. Ahern. 1989a. Multitemporal C-SAR for forest typing in Eastern Ontario. In Proc. of the Int. Geoscience and Remote Sensing (IGARSS'89) Symp. and 12th Canadian Symp. on Remote Sensing, July 1989, Vancouver, British Columbia. pp. 1376-1378.

Drieman, J.A., F.J. Ahern and I.G.W. Corns. 1989b. Visual interpretation of multipolarization C-SAR imagery of Alberta Boreal Forest. In Proc. of the Int. Geoscience and Remote Sensing (IGARSS'89) Symp. and 12th Canadian Symp. on Remote Sensing, July 1989, Vancouver, British Columbia. pp. 1401-1405.

Edwards, G. 1993. The integration of remote sensing and GIS: fundamental questions and new approaches. In Proc. of the 16th Canadian Symp. on Remote Sensing and 8th Symp. of AQT, June 1993, Sherbrooke, Québec. pp. 873-878.

Edwards, G. and J.M. Beaulieu. 1989. Segmentation of SAR imagery containing forest clearcuts. In Proc. of the Int. Geoscience and Remote Sensing (IGARSS'89) Symp. and 12th Canadian Symp. on Remote Sensing, July 1989, Vancouver, British Columbia. pp. 1195-1197.

Edwards, G. and S. Rioux. 1995. A detailed assessment of relative displacement error in clearcut boundaries derived from airborne C-band SAR. Can. J. Remote Sens. 21(2): 185-197.

Foody, G.M. 1986. An assessment of the topographic effects on SAR image tone. Can. J. Remote Sens. 12(2): 124-131.

Gillis, M.D., and D.G. Leckie. 1996. Forest inventory update in Canada. For. Chron. 72(2): 138-156.

Hall, R.J., A.R. Kruger, J. Scheffer, S.J. Titus and W.C. Moore. 1989. A statistical evaluation of Landsat-TM and MSS data for mapping forest clearcuts. For. Chron. 65 : 441-449.

Hilton, J.E. 1986. Use of Thematic Mapper satellite images for disturbance updating of timber/range maps. In Proc. of the 10th Canadian Symp. on Remote Sens., June 1986, Edmonton, Alberta. pp. 209-214.

Hinse, M., Q.H.T. Gwyn and F. Bonn. 1988. Radiometric correction of C-band imagery for topographic effects in regions of moderate relief. IEEE Trans. Geosc. Remote Sens. 26: 122-132.

Koch, B., B. Foerster and U. Ammer. 1992. The use of polarimetric radar remote sensing data for applications in forestry. In Proc. of the Central Symp. of the "International Space Year" Conf., April 1992, Munich, Germany, ESA ISY-1(2): 789-793.

Landry, R., F.J. Ahern, J.S. Paterson, D. Boucher and I. McKirdy. 1996. Évaluation de l'information obtenue à l'aide d'un RSO multifréquences et multipolarisations dans le contexte de la forêt boréale. In Proc. of the 9th Congress of the Quebec Association of Remote Sensing, May 1996, Québec, Québec. Available on CD-ROM.

Leblon, B., N. A. Mahmud and G. Jordan. 1995. Forest clearcut mapping using digital optical and radar remote sensing and GIS technologies: a literature review. Final Report, Canada/New-Brunswick Cooperation Agreement on Forest Development, Faculty of Forestry, University of New Brunswick, Fredericton, New Brunswick. 23 p. + appendix.

Leckie, D.G. 1984. Preliminary results of an examination of C-band synthetic aperture radar for forestry applications. In Proc. of the 8th Canadian Symp. on Remote Sensing and 4th Symp. of AQT, May 1983, Montréal, Québec. pp. 150-163.

Leckie, D.G. 1990. Synergism of synthetic aperture radar and visible/infrared data for forest type discrimination. Photogram. Eng. Remote Sens. 56(9): 1237-1246.

Leckie, D.G. 1997. The effect of environmental influences on RADARSAT images of forest land. In Proc. of the 19th Canadian Symp. on Remote Sensing, May 1997, Ottawa, Ontario. Available on CD-ROM.

Leckie, D.G. and K. J. Ranson. 1998. Forestry applications using imaging radar. In F.M. Henderson and A.J. Lewis (eds.). Principles and applications of imaging radar. Manual of Remote Sensing, Third edition, Volume 2, Chapter 9. pp. 435-501. John Wiley and Sons, Inc., New York.

Lee, J.K, J.C. Randolph, K.P. Lulla and M.R. Helfert. 1993. Interfacing remote sensing and geographic information systems for global environmental change research. Geocarto International 4: 7-18. Mancilla, B., K.P.B. Thomson, G. Edwards and M. Beauchemin. 1995. Analysis of factors influencing the visibility of forest clearcuts in radar images. In Proc. of the 17th Canadian Symp. on Remote Sensing, June 1995, Saskatoon, Saskatchewan. pp. 532-535.

Murtha, P.A. 1997. Radar Imaging Natural System (RAINS): Stumps and dead trees on RADARSAT. In Proc. of the 19th Canadian Symp. on Remote Sensing, June 1997, Ottawa, Ontario. Available on CD-ROM.

Murtha, P.A. 1998. Weather or not: Monitoring riparian strips in clearcuts with multi-temporal fine 2 mode RADARSAT data. In Proc. of the 20th Canadian Symp. on Remote Sensing, June 1998, Calgary, Alberta. Available on CD-ROM. 
Murtha, P.A. and S.J. Mitchell. 1998. Riparian leave strip monitoring with multi-temporal fine 2 mode RADARSAT data. In Proc. Am. Soc. Photogram. Remote Sens. Ann. Meeting, Bethesda, MD. Ranson, K.J. and G. Sun. 1994. Northern forest classification using temporal multifrequency and multipolarimetric SAR images. Remote Sens. Env. 47: 142-153.

Ranson, K.J. and G. Sun. 1997. An evaluation of AIRSAR and SIRC/X-SAR images for mapping northern forest attributes in Maine, USA. Remote Sens. Env. 59: 203-222.

Ranson, K.J., S. Saatchi and G. Sun. 1995. Boreal forest ecosystem characterization with SIR-C/XSAR. IEEE Trans. on Geosci. and Remote Sens. 33(4): 867-876.

Richards, J.A., G. Sun, and D. Simonett. 1987. L-band radar backscatter modeling of forest stands. IEEE Trans. Geosc. Remote Sens. 25: 487-498.

Rochon, G., C. Gosselin, M. Rheault, P. Vincent, K.B.P. Thomson, B. Goze Bertin, S. Poirier and F. Cavayas. 1986. Study of the use of SAR data for agriculture and forestry. In Proc. SAR Application Workshop, Frascati, Italy. ESA SP-264. pp. 81-93.

Rossignol, S. and F.J. Ahern. 1992. Synergism of simulated RADARSAT SAR and Landsat-TM for multitemporal forest change detection and clearcut delineation. In Proc. of the 15th Canadian Symp. on Remote Sensing, Toronto, Ontario. pp. 150-153.

Saatchi, S. and E. Rignot. 1997. Classification of boreal forest cover types using SAR images. Remote Sens. Env. 60: 270-281.

Sardar, A.M. 1997. The evolution of space-borne imaging radar systems: a chronological history. Can. J. Remote Sens. 23(3): 276-280. Schaller, S., I. McKirdy, F.J. Ahern and M. Akhavi. 1995. The use of multitemporal spaceborne SAR for discrimination of forest features in the Whitecourt, Alberta area. In Proc. of the 17th Canadian Symp. on Remote Sensing, June 1995, Saskatoon, Saskatchewan. pp. 700-705.
Warner, T., R. Bell and V. Singhroy. 1996. Local incidence angle effects on X-band and C-band radar backscatter of boreal forest communities. Can. J. Remote Sens. 22(3): 269-279.

Way, J.B., J. Paris, E. Kasischke, C. Slaughter, L. Viereck, N. Christensen, M.C. Dobson, F. Ulaby, J. Richards, A. Milne, A. Sieber, F.J. Ahern, D. Simonett, R. Hoffer, M. Imhoff and J. Weber. 1990. The effect of changing environmental conditions on microwave signatures of forest ecosystems: preliminary results of the March 1988 Alaskan aircraft SAR experiment. Int. J. Remote Sens. 11(7): 1119-1144.

Wedler, E., S. Pall and A. Jano. 1980. SAR image response over a conifer regeneration site. In Proc. of the 6th Canadian Symp. on Remote Sensing, Halifax, Nova Scotia. pp. 179-185.

Werle, D. 1989. Radar remote sensing for application in forestry. A literature review for investigators and potential users of SAR data in Canada. Report to the Canada Centre for Remote Sensing, Technology Transfer Program, Applications Division, Ottawa, Ontario. 42 p.

Werle, D., Y.J. Lee and R.J. Brown. 1986. The use of multispectral and radar remote sensing data for monitoring forest clearcut and regeneration sites on Vancouver Island. In Proc. of the 10th Canadian Symp. on Remote Sensing, June 1986, Edmonton, Alberta. pp. 319-329.

Yatabe, S.M. and D.G. Leckie. 1995. Clearcut and forest-type discrimination in satellite SAR imagery. Can. J. of Remote Sens. 21(4): $455-467$. 